\title{
A STRUCTURE OF THE COOLING SYSTEM
}

Some problems related to energetic flows in a cooling system of the combustion engine equipped with a non-conventional cooling circuit are described in this paper. The verification was carried out on a real diesel tractor engine by exploring the thermal balance. Actually, it is an assessment of the influence of alternative cooling liquid on the engine parameters with a particular attention to the flow of after-expansion energy into the cooling system for its further use. Thermal balance is evaluated by means of a reduced output number related to heat or energy chemically bound in fuel, energy led by the cooling system and energy corresponding to the effective output. The value of reduced output number gives attainable utility output per a supply unit of the given equipment (supposing that the energy of the coolant is used for the operation of other equipment, e.g. air-conditioning equipment).

The improvement of the output number of the combustion engine as an energetic source can be achieved through the use of exergic part of energy transformed in the combustion engine.

\section{Introduction}

The present trend of increase in prices for primary energy forces society to implement efficient transformations of energies or to design sets of machines using energy at lower potential levels. Equipment of this type is able to lower energetic demands both in industry and transport.

It is important to pay attention to this issue from the point of view of maintaining economic and trade balance. Apart from these criteria it is also necessary to bear in mind ecology and necessity to provide enough energy for the future. The creation of such a system is substantially affected by energetic machinery and equipment implemented in means of transport. To this group belong also internal combustion engines, either with continuous or discontinuous transformation of primary energy.

\section{Energy and exergy}

The combustion engine transforms primary energy chemically bound in fuel in the framework of the equation of thermal balance, which can be expressed in a simplified form by means of the following relation:

$$
Q_{p}=Q_{e}+Q_{c h}+Q_{v y f}+Q_{o l}+Q_{z v} \quad\left[\mathrm{~J} . \mathrm{s}^{-1}\right]
$$

Individual flows of energy are illustrated in Fig. 1 and their exploitation is illustrated too. In the figure we can see the value of accumulated after-expansion energy corresponding to the value of thermal energy related to the energy supplied in fuel. It is actually this part of thermal output, which is used by a non-conventional combustion engine whose definition is connected with its cooling circuit.
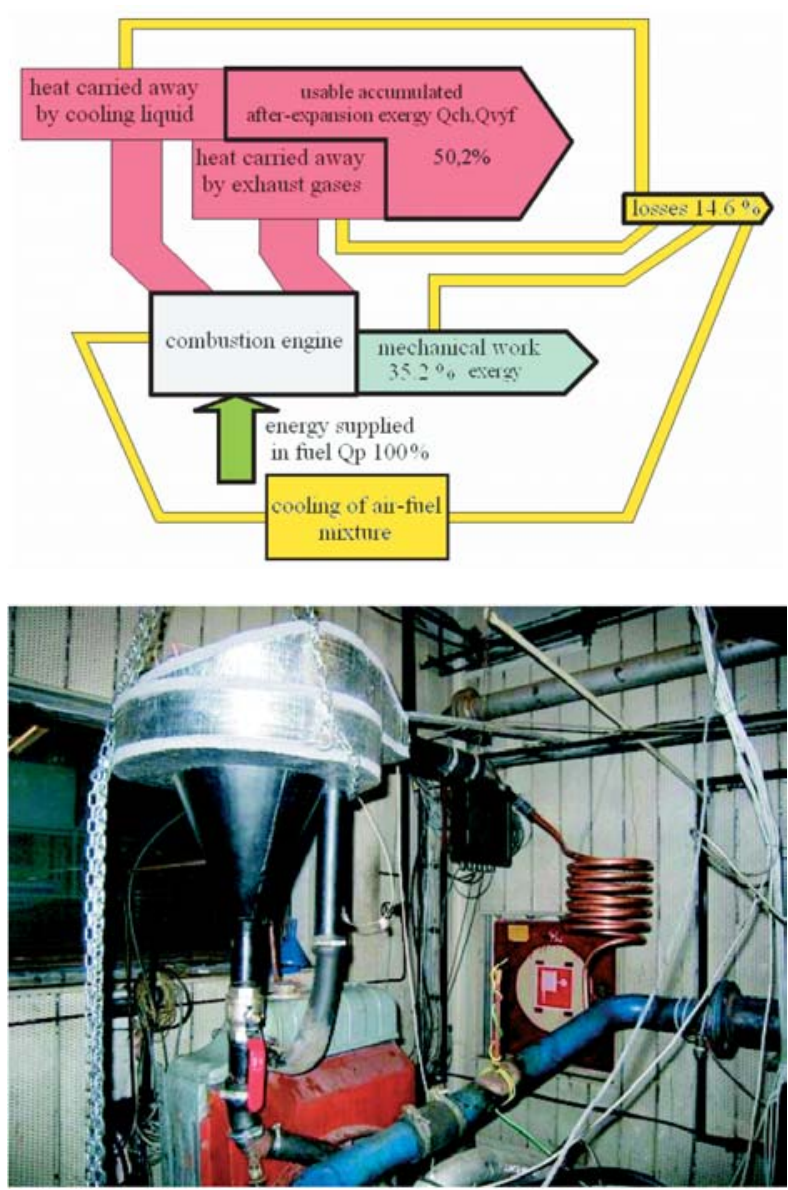

Fig. 1. Flows of energy and part of the conventional cooling system on a test bed [3]

\footnotetext{
* Vladimír Hlavňa, Dušan Sojčák, Dalibor Barta

University of Žilina, Slovak Republic, E-mail: vladimir.hlavna@fstroj.utc.sk, dusan.sojcak@fstroj.utc.sk, dalibor.barta@fstroj.utc.sk
} 
The closed non-conventional cooling circuit can form part of air conditioning or freezing equipment on the basis of absorption. The working medium from an air conditioning or freezing compartment with its specific physical properties will flow directly into the section of the combustion engine and will completely use the thermal gradient. In this way it is possible to form equipment for ergonomization and ecologization of the environment of means of transport and transportation of goods (e. g. foodstuff), requiring coldness.

To confirm the discussions concerning the use of exergic part of energy by means of a non-conventional cooling circuit some measurements of an alternative coolant have been made. The aim was to assess the influence of an alternative coolant on thermal balance of the diesel engine.

\subsection{Reduced coefficient of performance}

An energetic source such as a combustion engine can be assessed by the coefficient of performance (COP). The value of the coefficient of performance gives an attainable useful output per unit of supply of the given equipment. There is an objective to attain the highest possible level of the COP. In the case of the combustion engine to simplify the illustration of the COP value we used Carnot circulation - Fig. 2.

The presented unevenness 2 holds for the case when there is a possibility to efficiently use the heat in the cooling liquid and in exhaust gases in other convenient equipment. In such a case the value of the COP increases and energetic efficiency of the combustion engine also increases. The parameter attained in this way must correspond, as for its output, to the associated equipment making use of exergic flows of energy from the combustion engine.

$$
C O P_{M}=\frac{Q_{e}}{Q_{p}}<C O P_{M}=\frac{Q_{e}+Q_{c h}+Q_{v i f}}{Q_{p}}
$$

During experiments on the test stand the components $Q_{e}, Q_{p}$ and $Q_{c h}$ were investigated as priorities. The value of $Q_{c h}$ depends on flow and physical properties of the alternative coolant and for the attained thermal gradient_ $\mathrm{T}$ it can be expressed by means of the following relation:

$$
Q_{c h}=m_{A C H} \cdot c \cdot \Delta T \quad\left[\mathrm{~J} . \mathrm{s}^{-1}\right]
$$

With regard to the observed flows, the reduced coefficient of performance COPRED is given in the form [2]:

$$
C O P_{R E D}=\frac{Q_{q}+Q_{c h}}{Q_{p}}
$$

According to this number it is possible to determine the curve of efficient operation of a non-conventional combustion engine in the forms of $C O P_{R E D}=f\left(m_{A C H}\right)$ or $C O P_{R E D}=f\left(Q_{c h}\right)$. The functional dependence directly reflects the influence of constructional interventions into the cooling system of the combustion engine and enables to find an optimum of the value $C O P_{R E D}$.

This characteristic can be consequently implemented in a design of equipment making use of exergic heat flow.

\subsection{Model of an engine jacket}

For the purpose of an analytic solution of energetic flows a simplified physical model of the engine jacket was designed Fig. 3. It can serve for a reference observation of influence of constructional and flow requirements so that the flow of exergic part of energy is maintained as well as operational ability of the combustion engine from the point of view of thermal profiles in the cylinder lining. Fig. 3 shows part of volumetric networking of the jacket. The program packet FLUENT is used for solutions of flowing and energetic flows [1].

\section{Dependence $\mathrm{COP}_{\mathrm{RED}}$}

The experimentally obtained dependence - diagram in Fig. 4 - reflects the following facts at defining the $C O P_{R E D}$ :

- Comparison of thermal balance for cooling with water and alternative coolant,

- Cooling system without a constructional intervention.
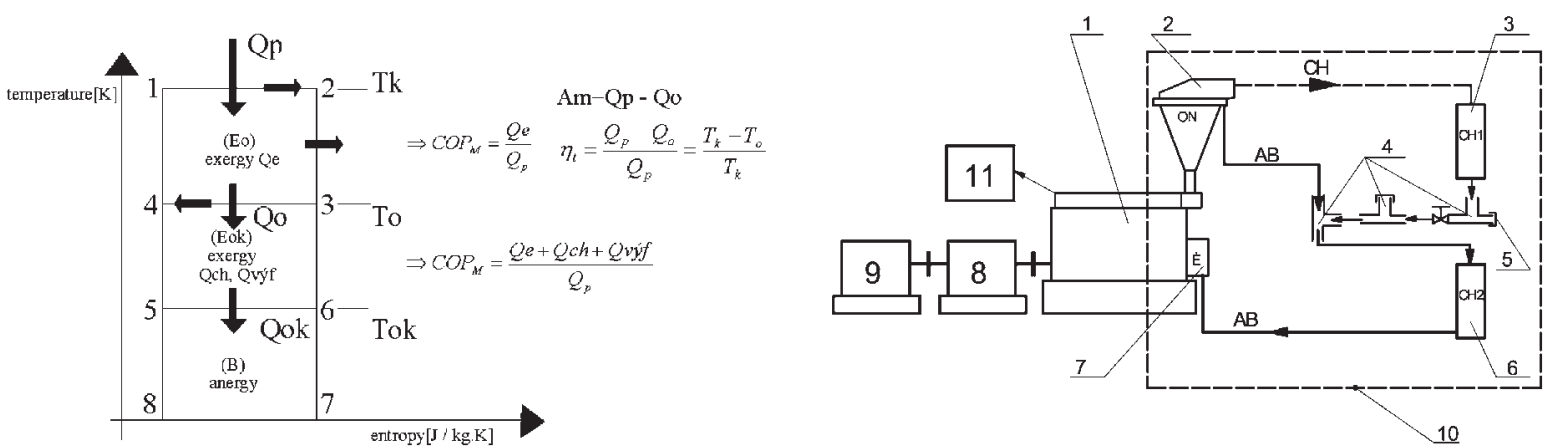

Fig. 2. Carnot circulation and coefficient of performance, scheme of trivalent energetic system on the basis of ICE 1 - combustion engine,

2 - vaporization container, 3 - coolant, 4 - connecting members, 5 - cover, 6 - coolant, 7 - internal pump of ICE, 8 - electric generator, 9 - heat pump, 10 - part of nonconventional cooling circuit under solution, 11 - equipment making use of exhaust gases heat [2]. 

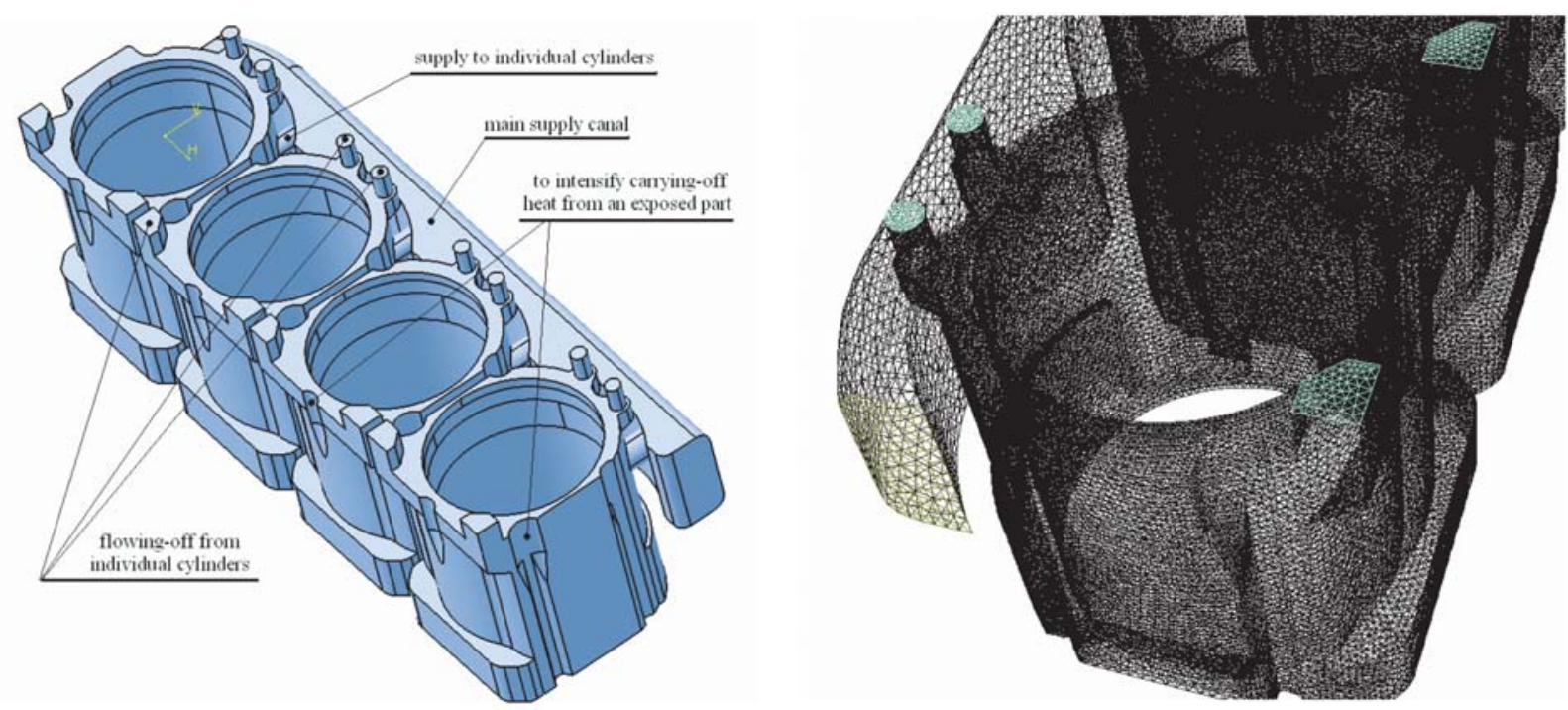

Fig. 3. Shape of the engine jacket for calculation of heat flows and view of part of volumetric networking of an engine jacket.

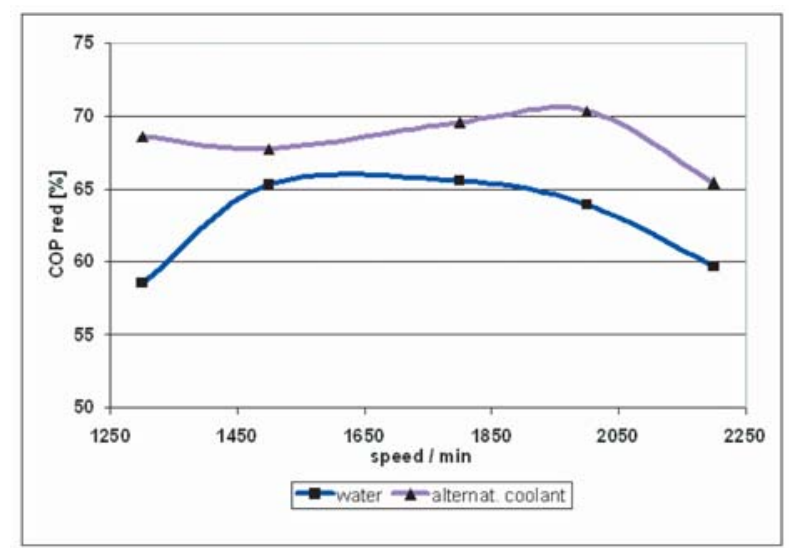

Fig. 4. Coefficient of performance in dependence on engine speed.

\section{A real performance number $\mathrm{COP}_{\text {red }}$}

The determination of a real coefficient of performance for the test stand can be carried out from two criteria:

A. a real coefficient of performance determining the quality of realization of the evaporation physical principal. It determines how much energy contained in the coolant will be transformed into other so called evaporation energy - heat. The mass flow of coolant and cooling output for an absorptive unit correspond to the value of evaporation heat at the defined evaporation efficiently,

B. a real coefficient of performance defining the cooling output achieved by the cooling unit. This assessment can be carried out only when the test stand is able to work at the maximum possible evaporation efficiency so that the operational ability and long life of the combustion engine is sustained.

$$
\text { A: } C O P_{r e d}=\frac{Q_{e}}{Q_{p}} \eta_{e l}+Q_{c h} \backslash Q_{p} U_{v y ́ p},
$$

$\eta_{e l}$ - efficiency of transformation of $Q_{e}$ e.g. into electric output, $U_{v y ́ p}$ - evaporation efficiency.

$$
U_{v y p}=\frac{Q_{v y p}}{Q_{c h}}=1-\frac{Q_{o c h}}{Q_{c h}}=1-\frac{\left(T_{v c h}-T_{v y c h}\right)}{\left(T_{v m}-T_{v y m}\right)}=1-\frac{d T^{c h}}{d T_{M}},
$$

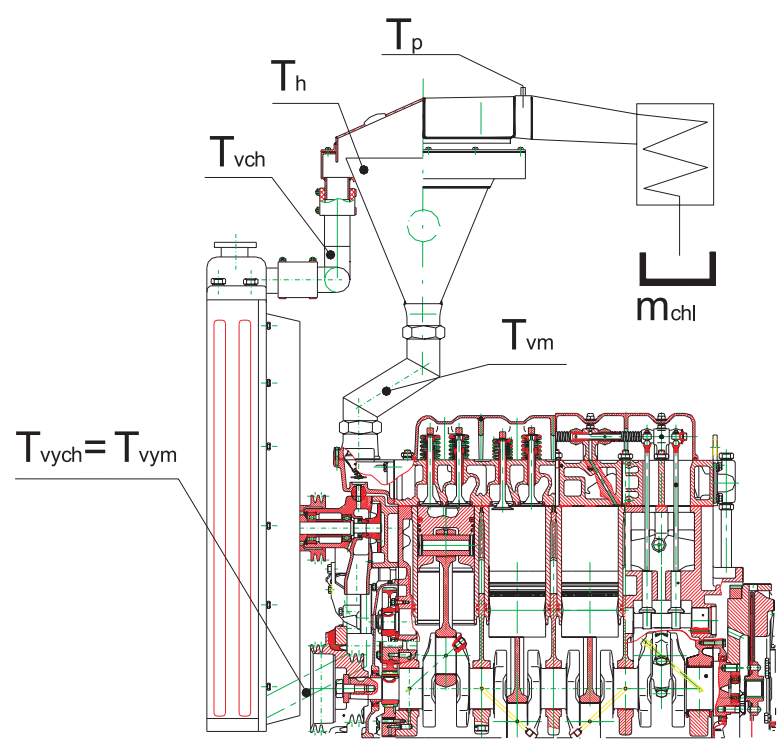

Fig. 5. $m_{c h l}$ - mass flow of coolant, $T_{v m}$ - temperature at the combustion engine exit, $T_{p}$ - temperature of vapor, $T_{h}$ - temperature of surface in the evaporation vessel, $T_{v c h}$ - temperature of lean solution leaving the evaporation vessel and entering the cooler, $T_{v y c h}$ and

$T_{v y m}$ - temperatures entering the combustion engine [2]. 


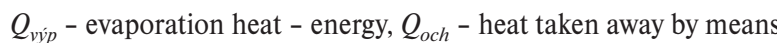
of the cooler, $T$ - temperatures are described in the figure, $d T_{c h}$ temperature gradient on the combustion engine cooler, $d T_{M}$ temperature gradient of the combustion engine. The attainment of maximum evaporation efficiency emerges from pressure conditions in which the absorptive cooling unit is to be operated. It is the case of low pressure conditions. So far we have assessed the cooperation in atmospheric conditions only. After the $C O P_{\text {red }}$ had been defined from the point of view of evaporation efficiency it is possible to define places for measurement.

$$
\begin{aligned}
& \text { B. } C O P_{r e d}=\frac{Q_{e}}{Q_{p}} \eta_{e l}+\frac{Q_{c h}}{Q_{p}} \eta_{n c h}, \\
& \eta_{n c h}=\frac{Q_{a b j}}{Q_{c h}},
\end{aligned}
$$

$\eta_{n c h}$ - efficiency of the non-conventional cooling circuit of the combustion engine. If the absorptive cooling unit achieves a higher cooling performance than the heat flow to the cooling system, the value of efficiency can be higher than 1 .

\section{Conclusion}

From the values gathered during the experiment on the test stand of the cooling combustion engine the following conclusions can be drawn:

- the change of coolant did not cause any undesired changes of outer speed characteristic for the sake of which the measurement was made,

- there was no increase in temperature of exhaust gases and oil,
- a positive fact is an increase of thermal flow into the cooling system, which increases the reduced coefficient of performance on average by $9 \%$.

It can, therefore, be concluded that the alternative coolant is from the point of view of thermal balance convenient, which provides a good assumption for a reconstruction of the engine on the test stand in compliance with technical requirements for a cooling process.

Part of the research is the determination of methodology for assessment of cooperation of the combustion engine with basic elements of the absorptive cooling equipment.

The first step is to define a cooling potential of the circuit in atmospheric conditions. The definition of a significant efficiency is not expected, but first experiments are aimed at outlining trends of observed parameters. In the circuit illustrated in Figs. 1 and 2 we are able to make use of $5 \%$ of energy accumulated in the coolant at the coolant condensate $0.12 \cdot 10^{-2} \mathrm{~kg} . \mathrm{s}^{-1}$. In future research it will be necessary to rebuilt the cooling system into lowpressure conditions and use suitable coolant. Subsequently, a significant increase of the coefficient of performance and mass flow of the coolant can be anticipated. In the conditions defined in this way it is necessary to maintain the operational ability of the combustion engine.

The contribution was created within the framework of the project Nr. APVT - 20 - 010302, which is supported by the Agency for Support of Science and Technology of the Slovak Republic.

\section{References}

[1] HLAVŇA, V., HUDÁK, A.: Some problems of ICE cooling systems, Konstrukcja, badania, eksploatacja, technologia pojazdow samochodowych i silnikow spalinowych, PAN Krakow, Zeszyt Nr. 26-27, 2003

[2] PIROCH, P.: More efficient utilizatiom of fuel in unconventional combustion engine, Žilinská univerzita, Žilina, 2002

[3] SOJČÁK, D.: A combustion engine with an unconventional cooling system, Žilinská univerzita, Žilina, 2003. 